Received Date : 03-Oct-2015

Revised Date : 09-Feb-2016

Accepted Date : 02-Mar-2016

Article type : Original Papers

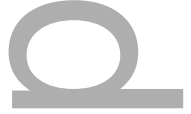

\title{
Nighttime Sleep in Parkinson`s disease - the potential use of Parkinson's KinetiGraph: A prospective comparative study
}

\author{
Lisa Klingelhoefer ${ }^{1,2}$, Alexandra Rizos ${ }^{2}$, Anna Sauerbier ${ }^{2}$, Sarah McGregor ${ }^{3}$
}

Pablo Martinez-Martin ${ }^{4}$, Heinz Reichmann ${ }^{1}$, Malcolm Horne ${ }^{3,5}$, K Ray Chaudhuri ${ }^{2}$

${ }^{1}$ Department of Neurology, Technical University Dresden, Fetscherstraße 74, Dresden,

Germany

${ }^{2}$ National Parkinson Foundation International Centre of Excellence, Biomedical research unit, Department of Neurology, King`s College Hospital and King`s College, Denmark Hill, London, UK

${ }^{3}$ Centre for Clinical Neurosciences and Neurological Research, St Vincent's Hospital

Melbourne, Fitzroy, Victoria, Australia

${ }^{4}$ National Center of Epidemiology and CIBERNED, Carlos III Institute of Health, Madrid, Spain.

${ }^{5}$ Florey Institute for Neuroscience and Mental Health, University of Melbourne, Parkville, Victoria, Australia

\section{Corresponding author:}

Lisa Klingelhoefer, MD, Clinical and Research Fellow, Department of Neurology, Technical University Dresden, Fetscherstraße 74, 01307 Dresden, Germany, Phone: 00493514583565, email: lisa.klingelhoefer@uniklinikum-dresden.de

\section{Running title:}

Nighttime sleep in PD - the use of PKG

This is the author manuscript accepted for publication and has undergone full peer review but has not been through the copyediting, typesetting, pagination and proofreading process, which may lead to differences between this version and the Version of Record. Please cite this article as $\underline{\text { doi: } 10.1111 / \text { ene.13015 }}$

This article is protected by copyright. All rights reserved 


\section{Key words:}

Parkinson`s disease, sleep, Parkinson`s KinetiGraph, actigraphy, PD, PKG, non-motor symptoms, NMS

\section{Conflict of Interest Statement:}

Lisa Klingelhoefer: reports grants from PDNMG and COST European Dystonia Research Network, outside the submitted work.

Alexandra Rizos: None

Anna Sauerbier: None

Sarah McGregor: reports that GKC has provided a travel grant in 2014 to attend the Movement Disorder Society Conference in Stockholm. GKC have provided an open research grant to the Florey Neuroscience Institute which in conjunction with other research grants is paid to St Vincent's Hospital Melbourne.

Pablo Martinez-Martin: reports personal fees from TEVA, Lundbeck, Italfarmaco, AbbVie, Movement Disorder Society, National School of Public Health (ISCIII), Complutense University, UCB and Universidad Politecnica de Madrid (summer course 2015), Editorial Viguera, Mundipharma, grants from Fondo de Investigación Sanitaria (FIS-ISCIII), IMSERSO (Ministry of Health PSI), Parkinson's UK, Parkinson's Disease Non-Motor Group, Reina Sofia Foundation, all outside the submitted work.

Heinz Reichmann: has served on advisory boards, given lectures and received research grants from Abbott, Abbvie, Bayer Health Care, Boehringer/Ingelheim, Brittania Pharmaceuticals, Cephalon, Desitin, GlaxoSmithKline, Lundbeck, Medtronic, MerckSerono, Novartis, Orion Pharma, Pfizer, Teva Pharmaceutical Industries, UCB, Valeant Pharmaceutical International, Zambon and Global Kinetics Corporation, all outside the submitted work.

Malcolm Horne: reports to be the manufacturer of the PKG and holds patents covering the PKG.

K Ray Chaudhuri: reports grants and personal fees from GSK Pharamaceuticals, Britannia Pharmaceuticals, AbbVie, UCB, Mundipharma, Neuronova, Boehringer Ingelheim, Global Kinetics Corporation, grants from Parkinson's UK, NIHR, PDNMG, EU, outside the submitted work.Abstract

Objective: Nighttime sleep disturbances are important non-motor symptoms (NMS) and key determinants of health related quality of life (HRQoL) in patients with Parkinson`s disease (PD). The Parkinson's KinetiGraph (PKG) can be used as an objective measure of different 
motor states and periods of immobility may reflect episodes of sleep. We aimed to evaluate whether PKG can be used as an objective marker of disturbed nighttime sleep in PD. Methods: In this prospective comparative study, data from PKG recordings over six consecutive 24-hour periods are compared with Hauser-diaries and scales focusing on motor state, sleep and HRQoL in PD-patients. 33 "non-sleepy" PD-patients (PD-NS) were compared with 30 PD-patients presenting with excessive daytime sleepiness (PD-EDS). The groups were matched for age, gender and Hoehn and Yahr state.

Results: In the PD-EDS group, subjective sleep reports correlated with the PKG's parameters for quantity and quality nighttime sleep but not in the PD-NS group. There were no significant correlations of the nighttime sleep quantity parameters of Hauser-diary with subjective sleep perception, neither in the PD-EDS nor in the PD-NS group.

Conclusions: This first PKG based study of nighttime sleep in PD suggests that PKG could be used to provide an easy to use and rough evaluation of aspects of nighttime sleep and one that could flag patients where polysomnography may be required. In sleepy PD-patients, for instance quantity and quality PKG parameters correlate with different aspects of sleep like insomnia, parasomnia, restless legs syndrome.

\section{Introduction}

Sleep disturbances in Parkinson`s disease (PD) are common, complex and multifactorial [1-3] as well as a major determinant of health related quality of life (HRQoL) [4-7]. Excessive daytime sleepiness (EDS) can be a sign of disturbed nighttime sleep in PD-patients [8-10]. There is a need to assess the underlying reason as treatment is to be tailored to the specific patient case and the specific sleep dysfunction [2,3]. Assessment requires objective sleep evaluation using polysomnography (PSG) regarded as gold standard.

However, in many countries such facilities are not widely available and PSG can not be routinely used as a screening tool as this requires overnight hospital admission as well as considerable clinical time and costs.

The Parkinson's KinetiGraph (PKG), a system consisting of algorithms operating on wrist worn triaxial accelerometry, can be used to objectively measure different motor states throughout the day [11]. An association between daytime sleep and the PKG's measurement of immobility has been reported [12] but the efficacy of PKG in monitoring sleep at nighttime has never been assessed. Aspects of disturbed nighttime sleep can be assessed in clinic by self-declaration in questionnaires or diaries. Absence of movement, measured by 
actigraphy can act as a proxy of nighttime sleep and correlates with PSG and subjective sleep measures (table 1) [13-17].

In this respect, the PKG could be useful in linking measures of nighttime sleep and motor parameters of PD in home conditions. The aim of this study was to evaluate the reliability of PKG as an objective remote marker of disturbed nighttime sleep in PD-patients.

In this study we relied on the following a priori presumptions:

- Period immobile as recorded by PKG of at least 14 minutes is regarded as an episode of "normal" sleep (table 1).

- Fragmented periods of mobility as shown by PKG would indicate "disturbed" sleep during night meaning the patient being awake or having abnormal sleep due to movements (e.g REM behavior disorder (RBD), Restless Legs Syndrome (RLS) (table 1) and [17]).

- Sleep assessment by PKG is however, not a measure of sleep architecture for which PSG is essential.

- PKG has been compared and validated against daytime PSG in PD [12].

Furthermore, we have relied on a repository of published literature outlining the evidence of actigraphy and diary assessments which have been used as surrogate measures for sleep in general as well as in PD (table 1).

\section{Methods}

\section{Patients}

We included non-demented patients with a diagnosis of idiopathic PD based on the UK Brain Bank criteria $[28,29]$ treated at King`s College Hospital London. All subjects provided consent and the study was approved by the ethical committee (UK REC reference 13/LO/1930).

Patients were screened using Epworth Sleepiness Score (ESS) [30] to select PD-patients with significant daytime somnolence. PD-patients whose ESS was 12 or higher were considered to suffer from EDS (PD-EDS group). Whereas PD-patients with ESS cut off score of less than 10 points were considered to have no significant daytime sleepiness and were referred to as "non-sleepy" (PD-NS group). Those with ESS scores of 10-11 in screening were not 
assessed further for the study to avoid overlap of PD-EDS and PD-NS group. For comparison both groups were matched for age, gender and Hoehn and Yahr state.

Exclusion criteria included patients whose medications were not stable four weeks prior and till the end of the study. Furthermore, patients with concomitant diseases causing sleep problems (e.g. obstructive sleep apnoea syndrome (OSAS), severe obesity, the use of sedatives/hypnotics) or conditions interfering PD-assessment (e.g. dementia) were excluded.

\section{Assessments}

- Patients' history and medication. Levodopa equivalent dosages (LED) [31]

- Mini-Mental-State-Examination - patients with <24 points were not included [32]

- Motor assessments:

- $\quad$ SCOPA motor part A, B, C [33, 34]

- $\quad$ Unified Parkinson`s disease rating scale (UPDRS) part IV [35]

- $\quad$ Abnormal involuntary movement scale (AIMS) [36, 37]

- Hoehn \& Yahr state [38].

- Non-motor and sleep assessments:

- Non-motor symptom questionnaire (NMSQuest) [39]

Epworth Sleepiness Score (ESS) [30]

- Parkinson's Disease Sleep Scale (PDSS-1) [40]

Hospital Anxiety and Depression Scale (HADS) [41]

HRQoL was assessed by means of the PD quality of life questionnaire (PDQ8) [42].

The PKG was worn at home on the more affected wrist for six consecutive 24-hour periods. It was only removed for washing or showering. Over the same period, 24-hours Hauserdiaries were completed [18] with nighttime being reported either in wake periods at night or retrospectively in the morning.

\section{Evaluation of $P K G$ and Hauser-diary}

The PKG (Global Kinetics Corporation, Australia) uses accelerometry to collect movement data, and algorithms that generate scores for bradykinesia (BK) and dyskinesia (DK) (figure 1a) [11]. Furthermore periods of immobility are reported (figure $1 \mathrm{~b}$ and 1c), as well as the output of a sensor recognising when it is off-wrist [12]. Periods of immobility are defined as two minute epochs in which the output of the BK-score algorithm reported a score at or below the threshold of -80 being consistent with complete immobility [12]. As summarised in table 1 , on the basis of published reports, these periods of immobility have a $85 \%$ 
concordance with the detection of sleep by ambulatory daytime PSG [12], absence of movement at nighttime, measured by actigraphy has $88-96.5 \%$ concordance to time asleep compared to overnight PSG [16, 20, 27] and highly correlates with PSG for differentiating sleep from wake states [14, 16, 26, 43].

As we compared the Hauser-diary as a subjective and the PKG as an objective measure of sleep, we have predefined to analyse the time period of 8PM till 8AM for the occurrence of sleep episodes as this time period should capture most likely the majority of nighttime sleep of all included patients.

Sleep as denoted by PKG was defined with the following concepts:

\section{Parameters for sleep quantity:}

- duration of nighttime rest: total time from the first onset of immobility (defined as the first occurrence of at least 14 minutes of continuous immobility ( 7 consecutive 2 minute epochs) after 8PM) until the end of the last immobility segment (defined as the last occurrence of at least 14 minutes of continuous immobility prior to $8 \mathrm{AM}$ ) in minutes (figure $1 \mathrm{~b}, \mathrm{c}$ )

- duration of sleep: total number of individual "sleep" segments in minutes in the duration of nighttime rest. The central two minutes of a 14 minute immobility segment (7 epochs) are called "sleep" when the subject is immobile for 4 of the 7 epochs constituting that 14 minute period (figure $1 b, c$ )

- duration of wakefulness: duration of nighttime rest minus duration of sleep (figure $1 \mathrm{~b}, \mathrm{c}$ )

\section{Parameters for sleep quality:}

- Proportion of time (PTI) asleep: percentage of "sleep" (as defined above) of the duration of rest

- PTI asleep >20min: These are defined as periods of 10 or more consecutive epochs (at least 20 minutes) of "sleep" (as defined above). This is to distinguish continuous "sleep" from fragmented "sleep" or "sleep" with many motor intrusions. The amount of time spent in this state was expressed as a percentage of the duration of rest to give a proportion of time in good quality "sleep".

- PTI awake >20min: These are defined as periods of 10 or more consecutive epochs (20 minutes) of wakefulness (i.e. not in "sleep" as defined above). We have assumed that these longer episodes of continuous movement most likely represent periods where the subject is 
not seeking to sleep and referred to as wake periods. The amount of time spent in this state was expressed as a percentage of the duration of rest to give a proportion of time being awake. Sleep as denoted by Hauser-diary was defined with the following concepts:

- duration of sleep: total time of marked 30 min periods of being "asleep" between 8PM and $8 \mathrm{AM}$ in minutes (figure 1d)

- duration of wakefulness: total time of marked 30 min periods of being awake marked as "off", "on", with "non-troublesome dyskinesia" or "troublesome dyskinesia" state between $8 \mathrm{PM}$ and $8 \mathrm{AM}$ in minutes (figure 1d)

\section{Statistics}

For statistical analyses the 24-hour assessment of the PKG and the Hauser-diary was separated to daytime and nighttime (defined as the time between 8PM till 8AM the next day). Therefore data of 6 days and 5 nights was obtained.

Parameters were tested for normal distribution using Kolmogorov-Smirnov-Z-test. Statistical analyses for comparisons were performed using $t$-test for normal distributed values and Mann-Whitney-test for not normal distributed values. Association of categorical parameters was tested using Chi-Square-test. Correlation analyses were performed with the Spearman rank correlation coefficient ( $\mathrm{r}_{\mathrm{s}}$-value). The correlation was considered: "weak" if the $\mathrm{r}_{\mathrm{s}}$-value was $<0.3$, "moderate" if $0.3-0.5$, "high" if $>0.5$. A p-value of less than 0.05 was considered to indicate statistical significance.

\section{$\underline{\text { Results }}$}

\section{Baseline characteristics and clinical outcome measures}

200 PD-patients were screened with the ESS in a movement disorders clinic over a 6 month period. Out of these, 86 patients with idiopathic PD could be assessed with the PKG and Hauser-diary whereas in the rest, further assessment was not performed owing to either an ESS score of 10-11 or due to fulfilling exclusion criteria (see methods). Furthermore, 23 PDpatients were excluded from statistical analyses because of non-compliance with Hauserdiaries or PKG, thus leaving 63 PD-patients for evaluation. 33 were categorised as "nonsleepy" (PD-NS, ESS <10) and 30 were "sleepy" (PD-EDS, ESS $\geq 12$ ). The mean ESS of PDNS patients was $5.94( \pm 2.38)$ (mean \pm standard deviation (SD)), and a range of 1 to 9 points, whereas the mean ESS of PD-EDS patients was $15.47( \pm 3.21)$ with a range from 12 to 23 $(\mathrm{p}<0.05)$. Significantly more patients with EDS reported to "find it difficult to stay awake 
during activities such as working, driving or eating" (NMSQuest-22) and to "have (been) unexpectedly fallen asleep during day" (PDSS item 15) ( $\mathrm{p}<0.05)$. Both groups were comparable in their motor disability (assessed with SCOPA motor A) and their motor complications including fluctuations and dyskinesia (assessed with SCOPA motor C, UPDRS IV, AIMS). Depression and anxiety scores (HADS, NMSQuest-13, -16, -17) as well as LED per day were also comparable in both groups. Baseline characteristics and outcome measures are summarised in table 2.

\section{Outcome of nighttime sleep quantity assessed by PKG and Hauser-diary (table 3)}

The mean duration of rest and of sleep was shorter and the mean duration of nighttime wakefulness tended to be longer in the PD-EDS group than in the PD-NS group, measured by both PKG and Hauser-diary but these differences were not significant (table 3).

The correlation coefficients and p-values for the following results are summarised in table 4. Both, the duration of sleep and the duration of wakefulness in the PD-EDS group (but not in the PD-NS group), measured by PKG, correlated significantly on a high level with the total burden of NMS of PD as measured by NMSQuest as well as the overall sleep disturbance as measured by PDSS (table 4). Specifically, significant correlations were found between the markers of nighttime sleep quantity measured by PKG with:

\footnotetext{
- sleep onset and maintenance insomnia (NMSQuest-23, PDSS-3), nocturnal restlessness (NMSQuest-26, PDSS-4 and -5),

nocturnal psychosis with distressing dreams and hallucinations (NMSQuest-14, PDSS-6),

- nocturnal motor symptoms like painful muscle cramps and dystonia (NMSQuest-25, PDSS-10 and -11).
}

In the PD-NS group only a moderate correlation between the duration of rest with difficulties to get or stay asleep at night (NMSQuest-23) was found. This finding suggests that these patients stay longer in bed and try to sleep.

In contrast, the data of the Hauser-diary showed only a moderate correlation between the duration of sleep as well as the duration of wakefulness with the NMSQuest-23 in the PDEDS group (sleep: $\mathrm{r}_{\mathrm{s}}=-0.38 ; \mathrm{p}=0.05$; wake: $\mathrm{r}_{\mathrm{s}}=0.35 ; \mathrm{p}=0.07$ ). None of the above presented pathological findings by PKG comprising different domains of NMSQuest and PDSS could be found in the analyses of the Hauser-diary. 


\section{Outcome of nighttime sleep quality assessed by PKG and Hauser-diary}

Values for the quality of nighttime sleep as the mean percentage of sleep as well as the percentage of good quality sleep were lower and the percentage of wakefulness higher in the PD-EDS group than in the PD-NS group, measured by PKG but the differences were not significant.

In the PD-EDS group the PTI asleep, the PTI asleep > 20min as well as the PTI awake $>20$ min measured by PKG correlated on a high level with the total burden of NMS as measured by NMSQuest as well as the overall sleep disturbances as measured by PDSS. Furthermore, we found moderate to high correlations of the nighttime sleep quality markers measured by PKG with different domains representing reasons for nocturnal sleep disturbances like:

sleep onset and maintenance insomnia,

- nocturnal restlessness as an indirect evidence of RLS,

- nocturnal psychosis

nocturnal motor symptoms with signs for RBD.

In the PD-NS group only a moderate correlation between the PTI asleep as well as the PTI awake $>20$ min with the appearance of distressing nocturnal hallucinations could be found. Other findings were not present in the PD-NS group.

\section{Influence on HRQoL (table 4)}

The PD-EDS group had a significant higher NMS burden (total NMSQuest-score, $\mathrm{p}<0.05$ ) and a trend towards worse HRQoL (PDQ8, p=0.07) than the PD-NS group. A moderate to high correlation of quantitative and qualitative nighttime sleep markers of the PKG was noted with the PDQ8 ( $\left.\mathrm{r}_{S}=|0.46-0.60|\right)$. This could only be found in the PD-EDS group and only for PKG and not for Hauser-diary parameter.

\section{Discussion}

To our knowledge this is the first study that:

- Compares subjective measures (self-reported rating scales assessed at one time point and Hauser-diary assessed continuously) with objective measures (PKG assessed continuously) of nighttime sleep in between "sleepy" (PD-EDS) and "non-sleepy" (PD-NS) PD-patients. 
- Attempts to evaluate relevant correlations between PKG to compare and contrast with Hauser-diary.

- Defines quantitative and qualitative markers of nighttime sleep of PKG.

- Investigates if PKG can differentiate between "sleepy" and "non-sleepy" PD-patients in real life clinical practise.

The key findings are as follows:

- We defined parameters for the quantity and quality of nighttime sleep as recorded by PKG.

- We confirm that the immobility and the mobility segments in nighttime PKG recording could serve as useful markers of periods asleep and of periods awake at night.

- Overall parameters of nighttime sleep measured by PKG and Hauser-diary between the PD-EDS and the PD-NS group were not significant different. Therefore, neither the PKG nor the Hauser-diary can discriminate between "sleepy" and "non-sleepy" PD-patients.

- PKG parameters of nighttime sleep in the PD-EDS group correlated significantly with several subjective clinical measures of sleep including sleep onset and maintenance insomnia, nocturnal RLS, nocturnal psychosis and nocturnal motor symptoms as well as with quality of life.

- This is not the case in the PD-NS group as well as for Hauser-diary parameters of nighttime sleep.

We used the ESS to differentiate between the "sleepy" study (PD-EDS) and the "non-sleepy" control (PD-NS) group. PD-patients with EDS usually are more likely to have disturbed nighttime sleep compared to PD-patients without EDS as reported by studies using nighttime PSG and daytime multiple sleep latency tests [3, 8-10, 44, 45]. We also used the ESS as this is a recommended screening tool and measure of daytime sleepiness by the Movement Disorder Society Sleep Scale Taskforce [46]. The ESS-score of 12 as a cut off for EDS was used and additionally we excluded patients with a score of 10-11 to avoid overlap [47-51]. To strengthen the ESS based cut off, we also used NMSQuest-22 and PDSS-15 which was correlated on a high level $\left(r_{S}=0.62, p=0.001\right)$ to ESS values confirming EDS in the PDS-EDS group. We are aware that the ESS is not a direct marker for disturbed nighttime sleep. As this study should first define parameters for nighttime sleep as measured by PKG and second evaluate whether the PKG can be used for nighttime sleep assessment in PD-patients, we 
aimed to compare the results of PKG with clinical data obtained from validated scales and questionnaires. As the PDSS, a validated scale for identifying nighttime sleep problems [40] as well as the NMSQuest, a measure of the burden of NMS in PD-patients [52] were outcome measures, we could not use these for screening patients. We attempted to control for other confounders such as age (sleep disturbances increase with age [53]), motor stage and motor complications (nocturnal motor symptoms contribute to disturbed nighttime sleep [3]), depression and anxiety and medication (LED per day) by matching the two groups in this regard. Therefore, we were relatively certain of examining a representative PD-population with a "sleepy" and a comparable "non-sleepy" group and thus reasonably conclude that disturbed nighttime sleep was responsible for the EDS in the PD-EDS group.

Our results suggest that in PD-EDS patients, it is possible to evaluate the presence of nighttime sleep dysfunctions by sleep quantity and quality PKG parameters which may not be otherwise detected without PSG. PD-EDS patients appear to have more interrupted sleep compared to PD-NS patients although this is not statistical significant. This might be because the parameters used may not be completely robust to accurately reflect periods asleep. However, the definition of the nighttime sleep parameters used in this study is based on actigraphic studies (table 1) and at least 14 minutes of continuous immobility seem to be a reasonable parameter to identify sleep periods. Differentiating aspects of PKG are reflected in correlations on high levels of all PKG sleep parameters with key aspects of sleep dysfunction in PD. Such correlations were only available in the PD-EDS and not in the PD-NS group, neither for Hauser-diary sleep parameters. These correlations included sleep dysfunctions such as insomnia, possibly aspects of parasomnia, RLS and RBD. The clinical implications therefore are that abnormal PKG readings in PD-EDS patients at nighttime should alert the physician to specifically look for aspects of sleep disorders. There was only a trend towards a higher load of distressing dreams and distressing hallucinations at night in the PD-EDS patients in comparison to the PD-NS patients in self declared questionnaires. Therefore, the observed differences shown by PKG suggest that this simple and easy to use technique unravels disturbed nighttime sleep in patients who recognise to suffer from daytime sleepiness when other clinical measures and patients themselves do not recognise specific nighttime problems. Happe et al. and other studies showed that PD-patients have subjectively and objectively disturbed nighttime sleep as compared with healthy controls but may perceive their sleep differently and therefore do not rate an objectively disturbed sleep as poor sleep [1, $54,55]$. Furthermore it is a known problem that insomniacs in general mispercept their sleep 
as shown by contradictory findings in subjective and objective measures of sleep like PSG [56]. In our study this is shown by greater periods of sleep and wakefulness by Hauser-diary compared to PKG in both groups.

Our findings support the results of - to our knowledge - only two other studies comparing subjective and objective sleep parameters in PD-patients with healthy controls [1, 13]. Stavitsky et al. [13] compared subjective self-reported data of nighttime sleep with actigraphic data. Similar to our results they found that based on the sleep-diary there were no differences between their PD study group and the healthy controls in the average total sleep time [13]. Furthermore significant correlations between subjective sleep measures and the actigraphic measures could only be found in their PD study group and indicated that actigraphy is an appropriate method to measure sleep quality in PD [13]. Happe et al. [1] also investigated the subjective versus objective perception of sleep in PD-patients in comparison with healthy elderly controls. They showed that PD-patients suffer from poorer subjective sleep and decreased objective sleep efficiency compared to healthy controls. Both studies could show that in general PD-patients suffer from poorer nighttime sleep in comparison to healthy controls using objective and subjective parameters but did not compare PD-patients with each other. To our knowledge there is no study comparing subjective and objective sleep parameters in between PD-patients.

The advantage of actigraphy in sleep medicine in comparison to PSG has been shown in general [57]. Especially in PD known for its notorious fluctuations which may occur within and across days, the promising advantage of a remote monitoring is: to measure disease related outcomes in real live environment; the possibility to extend the duration of measurement over a couple of days to enhance reliability and to provide a broad perspective on the individual sleep variability; the possibility of repetitive assessments. The PKG in comparison to actigraphy additionally offers measurement of motor function by providing severity scores of bradykinesia and dyskinesia. This might help to differentiate between severe bradykinesia and sleep, both presented as immobility by actigraphy. Furthermore the PKG provides both daytime as well as nighttime sleep which actigraphy normally does not provide.

The Movement Disorder Society Sleep Scale Taskforce concluded as well that scales and questionnaires alone may not adequately capture the fluctuating nature of sleep disturbances and may not disentangle the many faces of sleep disorders in PD [46]. More practical and 
specific tools are needed to screen for sleep disturbance and daytime sleepiness in larger numbers of PD-patients [46].

There are clear limitations of our study. How can we be sure that immobility measured by PKG corresponds to episodes of sleep and how can one distinguish between severe bradykinesia and sleep episodes? We based our a priori presumptions on the findings of Kotschet et al. [12] showing that episodes of immobility defined by a BK-score at or below the threshold of -80 correspond to sleep as a strong concordance between these episodes of immobility and daytime ambulatory PSG could be found. Furthermore, PD-patients with EDS presented with significant higher proportions of immobility than PD-patients without EDS [12]. There is no absolute guaranty that all these episodes of immobility correspond to sleep and do not partly represent severe bradykinetic state or somnolence but it gets more likely with a longer duration of immobility episodes, with BK-scores of much lesser severity occurring alongside these episodes and as these episodes also occur in healthy controls. As we focused on nighttime sleep, especially on disturbed nighttime sleep meaning a repetitive interruption of immobility for a longer time period over several hours measured by PKG, we do not suspect that a possible overlap of severe bradykinetic state and sleep at some time points interferes with our results. Furthermore, we decided to compare PD-patients with each other and not with a healthy control population as we wanted to investigate whether in matched groups concerning PD motor state and therefore assumable similar BK-scores measured by PKG still a relevant difference could be found concerning immobility and mobility. As the PD-EDS and PD-NS group are well matched concerning possible confounders like motor condition, LED as well as depression and anxiety, we provide hereby a further argument for immobility representing episodes of sleep and not severe bradykinesia. A correlation of nighttime PSG and PKG would be however essential in future studies.

In addition, nighttime sleep quantity and quality parameters assessed by the PKG correlated significantly with the PDQ8 only in the PD-EDS group providing an indirect indicator of the negative impact of disturbed nighttime sleep and EDS on the HRQoL in PD-patients [7, 58]. Hence we could show that the role of PKG use in the PD-EDS group ties in directly and indirectly with HRQoL as well.

\section{$\underline{\text { Conclusion }}$}


As it is known that nighttime sleep disturbances occur more often in PD-patients in comparison to healthy controls and furthermore that sleep as a NMS has a major impact on HRQoL, it is important to recognise patients suffering from disturbed nighttime sleep. As studies could show that the combination of subjective and objective sleep assessments can differ between PD-patients and healthy controls, our study showed that the use of subjective sleep assessments combined with objective sleep parameters obtained from the PKG can differentiate between PD-patients with and without disturbed nighttime sleep. The PKG provides the clinicians with information about sleep quantity and quality and helps to differentiate between the different aspects of disturbed nighttime sleep like insomnia, parasomnia, RLS and RBD. This is important to decide for further need of investigations and to address treatment individually.

Funding: International Parkinson`s disease non motor group (PDNMG) PDNMG/Gr/LK/1.References

[1] Happe S, Klosch G, Lorenzo J, Kunz D, Penzel T, Roschke J, Himanen SL, Gruber G, Zeitlhofer J (2005) Perception of sleep: subjective versus objective sleep parameters in patients with Parkinson's disease in comparison with healthy elderly controls. Sleep perception in Parkinson's disease and controls. J Neurol 252, 936-943.

[2] Klingelhoefer L, Sokolov E, Chaudhuri KR (2014) Therapeutic options for nocturnal problems in Parkinson's disease and atypical parkinsonian disorders. J Neural Transm 121 Suppl 1, S25-31.

[3] Dhawan V, Healy DG, Pal S, Chaudhuri KR (2006) Sleep-related problems of Parkinson's disease. Age Ageing 35, 220-228.

[4] Martinez-Martin P, Rodriguez-Blazquez C, Kurtis MM, Chaudhuri KR (2011) The impact of non-motor symptoms on health-related quality of life of patients with Parkinson's disease. Mov Disord 26, 399-406.

[5] Hinnell C, Hurt CS, Landau S, Brown RG, Samuel M (2012) Nonmotor versus motor symptoms: how much do they matter to health status in Parkinson's disease? Mov Disord 27, 236-241.

[6] Happe S, Berger K (2003) The influence of poor sleep on quality of life in patients with Parkinson's disease. A prospective study. Somnologie 7, 134-139. 
[7] Schrempf W, Brandt MD, Storch A, Reichmann H (2014) Sleep disorders in Parkinson's disease. J Parkinsons Dis 4, 211-221.

[8] Tandberg E, Larsen JP, Karlsen K (1999) Excessive daytime sleepiness and sleep benefit in Parkinson's disease: a community-based study. Mov Disord 14, 922-927.

[9] van Hilten JJ, Weggeman M, van der Velde EA, Kerkhof GA, van Dijk JG, Roos RA (1993) Sleep, excessive daytime sleepiness and fatigue in Parkinson's disease. $J$ Neural Transm Park Dis Dement Sect 5, 235-244.

[10] Arnulf I (2005) Excessive daytime sleepiness in parkinsonism. Sleep Med Rev 9, 185200.

[11] Griffiths RI, Kotschet K, Arfon S, Xu ZM, Johnson W, Drago J, Evans A, Kempster P, Raghav S, Horne MK (2012) Automated assessment of bradykinesia and dyskinesia in Parkinson's disease. J Parkinsons Dis 2, 47-55.

[12] Kotschet K, Johnson W, McGregor S, Kettlewell J, Kyoong A, O'Driscoll DM, Turton AR, Griffiths RI, Horne MK (2014) Daytime sleep in Parkinson's disease measured by episodes of immobility. Parkinsonism Relat Disord.

[13] Stavitsky K, Saurman JL, McNamara P, Cronin-Golomb A (2010) Sleep in Parkinson's disease: a comparison of actigraphy and subjective measures. Parkinsonism Relat Disord 16, 280-283.

[14] Jean-Louis G, Zizi F, von Gizycki H, Hauri P (1999) Actigraphic assessment of sleep in insomnia: application of the Actigraph Data Analysis Software (ADAS). Physiol Behav 65, 659-663.

[15] Ancoli-Israel S, Cole R, Alessi C, Chambers M, Moorcroft W, Pollak CP (2003) The role of actigraphy in the study of sleep and circadian rhythms. Sleep 26, 342-392.

[16] Cole RJ, Kripke DF, Gruen W, Mullaney DJ, Gillin JC (1992) Automatic sleep/wake identification from wrist activity. Sleep 15, 461-469.

[17] Nass A, Nass RD (2008) Actigraphic evidence for night-time hyperkinesia in Parkinson's disease. Int J Neurosci 118, 291-310. 
[18] Hauser RA, Friedlander J, Zesiewicz TA, Adler CH, Seeberger LC, O'Brien CF, Molho ES, Factor SA (2000) A home diary to assess functional status in patients with Parkinson's disease with motor fluctuations and dyskinesia. Clin Neuropharmacol 23, $75-81$.

[19] Hauser RA, Deckers F, Lehert P (2004) Parkinson's disease home diary: further validation and implications for clinical trials. Mov Disord 19, 1409-1413.

[20] Jean-Louis G, Kripke DF, Mason WJ, Elliott JA, Youngstedt SD (2001) Sleep estimation from wrist movement quantified by different actigraphic modalities. $J$ Neurosci Methods 105, 185-191.

[21] Kushida CA, Chang A, Gadkary C, Guilleminault C, Carrillo O, Dement WC (2001) Comparison of actigraphic, polysomnographic, and subjective asessment of sleep parameters in sleep-disordered patients. Sleep Med, 398-396.

[22] Monk TH, Buysse DJ, Rose LR (1999) Wrist actigraphic measures of sleep in space. Sleep 22, 948-954.

[23] Ancoli-Israel S, Clopton P, Klauber MR, Fell R, Mason WJ (1997) Use of wrist activity for monitoring sleep/wake in demented nursing home patients. Sleep 20, 2427.

[24] Sadeh A (1996) Evaluating night wakings in sleep-disturbed infants: a methodological study of parental reports and actigraphy. Sleep 19, 757-762.

[25] Gorny SW, Allen RP, Krausman DT, Early CJ (1996) Parametric analyses of factors affecting accuracy for detection of wake epochs after sleep onset based on wrist actigraphy data. Sleep Res. 25:490.

[26] Jean-Louis G, von Gizycki H, Zizi F, Fookson J, Spielman A, Nunes J, Fullilove R, Taub H (1996) Determination of sleep and wakefulness with the actigraph data analysis software (ADAS). Sleep 19, 739-743.

[27] Sadeh A, Sharkey KM, Carskadon MA (1994) Activity-based sleep-wake identification: An empirical test of methodological issues Sleep Breath 17, 201-207. 
[28] Hughes AJ, Daniel SE, Kilford L, Lees AJ (1992) Accuracy of clinical diagnosis of idiopathic Parkinson's disease: a clinico-pathological study of 100 cases. J Neurol Neurosurg Psychiatry 55, 181-184.

[29] Lees AJ, Hardy J, Revesz T (2009) Parkinson's disease. Lancet 373, 2055-2066.

[30] Johns MW (1991) A new method for measuring daytime sleepiness: the Epworth sleepiness scale. Sleep 14, 540-545.

[31] Tomlinson CL, Stowe R, Patel S, Rick C, Gray R, Clarke CE (2010) Systematic review of levodopa dose equivalency reporting in Parkinson's disease. Mov Disord 25, 2649-2653.

[32] Dubois B, Burn D, Goetz C, Aarsland D, Brown RG, Broe GA, Dickson D, Duyckaerts C, Cummings J, Gauthier S, Korczyn A, Lees A, Levy R, Litvan I, Mizuno Y, McKeith IG, Olanow CW, Poewe W, Sampaio C, Tolosa E, Emre M (2007) Diagnostic procedures for Parkinson's disease dementia: recommendations from the movement disorder society task force. Mov Disord 22, 2314-2324.

[33] Marinus J, Visser M, Stiggelbout AM, Rabey JM, Martinez-Martin P, Bonuccelli U, Kraus PH, van Hilten JJ (2004) A short scale for the assessment of motor impairments and disabilities in Parkinson's disease: the SPES/SCOPA. J Neurol Neurosurg Psychiatry 75, 388-395.

[34] Martinez-Martin P, Benito-Leon J, Burguera JA, Castro A, Linazasoro G, MartinezCastrillo JC, Valldeoriola F, Vazquez A, Vivancos F, del Val J, van Blercom N, Frades B (2005) The SCOPA-Motor Scale for assessment of Parkinson's disease is a consistent and valid measure. J Clin Epidemiol 58, 674-679.

[35] Fahn S, Elton RL (1987) UPDRS Development Committee. Unified Parkinson's Disease Rating Scale. In Recent Developments in Parkinson's Disease., Fahn S, Marsden CD, Calne DB, Goldstein M, eds. Florham Park, pp. 153-163.

[36] Colosimo C, Martinez-Martin P, Fabbrini G, Hauser RA, Merello M, Miyasaki J, Poewe W, Sampaio C, Rascol O, Stebbins GT, Schrag A, Goetz CG (2010) Task force report on scales to assess dyskinesia in Parkinson's disease: critique and recommendations. Mov Disord 25, 1131-1142. 
[37] Guy W (1976) ECDEU Assessment Manual for Psychopharmacology In US Department of Health, Education and Welfare, Public Health Service, Alcohol, Drug Abuse and Mental Health Administration, NIMH Psychopharmacology Research Branch, Division of Extramural Research Programs, Rockville MD, ed.

[38] Hoehn MM, Yahr MD (1967) Parkinsonism: onset, progression and mortality. Neurology 17, 427-442.

[39] Chaudhuri KR, Martinez-Martin P, Schapira AH, Stocchi F, Sethi K, Odin P, Brown RG, Koller W, Barone P, MacPhee G, Kelly L, Rabey M, MacMahon D, Thomas S, Ondo W, Rye D, Forbes A, Tluk S, Dhawan V, Bowron A, Williams AJ, Olanow CW (2006) International multicenter pilot study of the first comprehensive self-completed nonmotor symptoms questionnaire for Parkinson's disease: the NMSQuest study. Mov Disord 21, 916-923.

[40] Chaudhuri KR, Pal S, DiMarco A, Whately-Smith C, Bridgman K, Mathew R, Pezzela FR, Forbes A, Hogl B, Trenkwalder C (2002) The Parkinson's disease sleep scale: a new instrument for assessing sleep and nocturnal disability in Parkinson's disease. J Neurol Neurosurg Psychiatry 73, 629-635.

[41] Zigmond AS, Snaith RP (1983) The hospital anxiety and depression scale. Acta Psychiatr Scand 67, 361-370.

[42] Jenkinson C, Fitzpatrick R, Peto V, Greenhall R, Hyman N (1997) The Parkinson's Disease Questionnaire (PDQ-39): development and validation of a Parkinson's disease summary index score. Age Ageing 26, 353-357.

[43] Blood ML, Sack RL, Percy DC, Pen JC (1997) A comparison of sleep detection by wrist actigraphy, behavioral response, and polysomnography. Sleep 20, 388-395.

[44] Rye DB, Bliwise DL, Dihenia B, Gurecki P (2000) FAST TRACK: daytime sleepiness in Parkinson's disease. J Sleep Res 9, 63-69.

[45] Arnulf I, Konofal E, Merino-Andreu M, Houeto JL, Mesnage V, Welter ML, Lacomblez L, Golmard JL, Derenne JP, Agid Y (2002) Parkinson's disease and sleepiness: an integral part of PD. Neurology 58, 1019-1024. 
[46] Hogl B, Arnulf I, Comella C, Ferreira J, Iranzo A, Tilley B, Trenkwalder C, Poewe W, Rascol O, Sampaio C, Stebbins GT, Schrag A, Goetz CG (2010) Scales to assess sleep impairment in Parkinson's disease: critique and recommendations. Mov Disord 25, 2704-2716.

[47] Kumar S, Bhatia M, Behari M (2003) Excessive daytime sleepiness in Parkinson's disease as assessed by Epworth Sleepiness Scale (ESS). Sleep Med 4, 339-342.

[48] Brodsky MA, Godbold J, Roth T, Olanow CW (2003) Sleepiness in Parkinson's disease: a controlled study. Mov Disord 18, 668-672.

[49] Hobson DE, Lang AE, Martin WR, Razmy A, Rivest J, Fleming J (2002) Excessive daytime sleepiness and sudden-onset sleep in Parkinson disease: a survey by the Canadian Movement Disorders Group. JAMA 287, 455-463.

[50] Tan EK, Lum SY, Fook-Chong SM, Teoh ML, Yih Y, Tan L, Tan A, Wong MC (2002) Evaluation of somnolence in Parkinson's disease: comparison with age- and sex-matched controls. Neurology 58, 465-468.

[51] Johns MW (2000) Sensitivity and specificity of the multiple sleep latency test (MSLT), the maintenance of wakefulness test and the epworth sleepiness scale: failure of the MSLT as a gold standard. J Sleep Res 9, 5-11.

[52] Chaudhuri KR, Sauerbier A, Rojo JM, Sethi K, Schapira AH, Brown RG, Antonini A, Stocehi F, Odin P, Bhattacharya K, Tsuboi Y, Abe K, Rizos A, Rodriguez-Blazquez C, Martinez-Martin P (2015) The burden of non-motor symptoms in Parkinson's disease using a self-completed non-motor questionnaire: a simple grading system.

Parkinsonism Relat Disord 21, 287-291.

[53] Asplund R (1999) Sleep disorders in the elderly. Drugs Aging 14, 91-103.

[54] Edinger JD, Fins AI (1995) The distribution and clinical significance of sleep time misperceptions among insomniacs. Sleep 18, 232-239.

[55] Merino-Andreu M, Arnulf I, Konofal E, Derenne JP, Agid Y (2003) Unawareness of naps in Parkinson's disease and in disorders with excessive daytime sleepiness. Neurology 60, 1553-1554. 
[56] Engleman HM, Hirst WS, Douglas NJ (1997) Under reporting of sleepiness and driving impairment in patients with sleep apnoea/hypopnoea syndrome. J Sleep Res $\mathbf{6}$, $272-275$.

[57] Mayer G, Jennum P, Riemann D, Dauvilliers Y (2011) Insomnia in central neurologic diseases--occurrence and management. Sleep Med Rev 15, 369-378.

[58] Rye DB (2006) Excessive daytime sleepiness and unintended sleep in Parkinson's disease. Curr Neurol Neurosci Rep 6, 169-176.

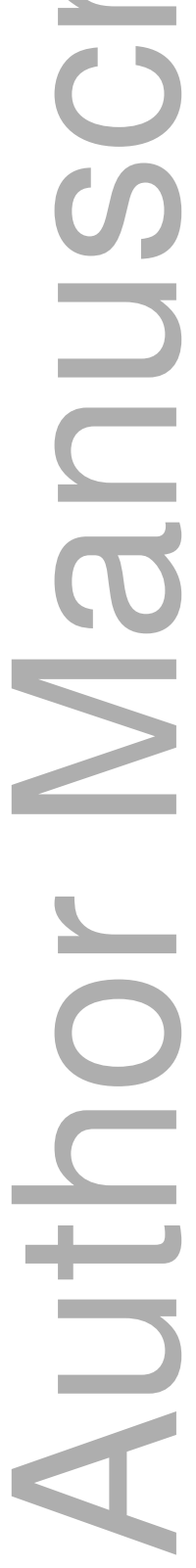


Table 1: Summarising the literature on studies using actigraphy and diaries for nighttime sleep assessment providing basic principles and findings on which the study design and presumptions of the present study are based. (ACT=Actigraphy, PSG=Polysomnography, $\mathrm{PD}=$ Parkinson`s disease, $\mathrm{PKG}=$ Parkinson`s Kinetigraph)

\begin{tabular}{|c|c|c|c|}
\hline $\begin{array}{c}\text { Author / Year / } \\
\text { Reference }\end{array}$ & Methodology of the study & Conclusion of the study & $\begin{array}{c}\text { Conclusion for the design and definition } \\
\text { of nighttime sleep parameters for the } \\
\text { present study }\end{array}$ \\
\hline $\begin{array}{l}\text { Kotschet et al. } \\
2014 \text { [12] }\end{array}$ & $\begin{array}{l}\text { Wrist PKG and daytime } \\
\text { ambulatory PSG in seven PD- } \\
\text { patients }\end{array}$ & $\begin{array}{l}\text { - periods of immobility measured by PKG have a } 85 \% \\
\text { concordance with the detection of sleep by daytime PSG } \\
\text { - complete immobility is defined as all two minute epochs } \\
\text { with an output of the mobility score algorithm at or below } \\
\text { the specific threshold of - } 80\end{array}$ & $\begin{array}{l}\text { The PKG can assess episodes of immobility } \\
\text { during daytime which have a high } \\
\text { concordance to episodes of sleep assessed } \\
\text { by daytime PSG. Therefore, the PKG might } \\
\text { also be useful to assess periods of } \\
\text { immobility at nighttime which correspond } \\
\text { to sleep. }\end{array}$ \\
\hline $\begin{array}{l}\text { Griffiths et al. } \\
2012[11]\end{array}$ & $\begin{array}{l}\text { Assessment of bradykinesia } \\
\text { and dyskinesia by PKG in } 34 \\
\text { PD patients and } 10 \text { age- } \\
\text { matched controls }\end{array}$ & $\begin{array}{l}\text { - PKG provides quantitative measures of severity and } \\
\text { proportion of time spent at various levels of bradykinesia } \\
\text { and dyskinesia } \\
\text { - recordings were made from the more affected wrist } \\
\text { concerning PD motor symptoms }\end{array}$ & $\begin{array}{l}\text { As defined in this article, the PKG should } \\
\text { be able to discriminate between } \\
\text { bradykinesia and episodes of complete } \\
\text { immobility which correspond to sleep } \\
\text { episodes as shown for daytime assessment. } \\
\text { Furthermore, the PKG should be worn on } \\
\text { the more affected wrist for reliable } \\
\text { assessment of motor states during daytime. }\end{array}$ \\
\hline
\end{tabular}

This article is protected by copyright. All rights reserved 


\begin{tabular}{|c|c|c|c|}
\hline $\begin{array}{l}\text { Stavitsky et al. } \\
2010 \text { [13] }\end{array}$ & $\begin{array}{l}\text { 24-hour wrist ACT and a sleep } \\
\text { diary over a seven day period } \\
\text { were compared in } 30 \text { PD- } \\
\text { patients and } 14 \text { healthy } \\
\text { controls }\end{array}$ & $\begin{array}{l}\text { - PD-patients presented with more sleep problems than } \\
\text { healthy controls } \\
\text { - in PD-patients scores on subjective sleep measures } \\
\text { correlated with ACT-derived estimates of sleep quality } \\
\text { whereas no correlations could be found in any of the ACT } \\
\text { sleep variables with self-reported measures of sleep in } \\
\text { healthy controls } \\
\rightarrow \text { ACT is an appropriate method of measuring sleep quality } \\
\text { in PD }\end{array}$ & $\begin{array}{l}\text { In spite of bradykinesia (presenting as } \\
\text { movements with smaller amplitude and } \\
\text { longer duration) which might interfere with } \\
\text { ACT, especially in differentiation } \\
\text { immobility (corresponding to sleep) and } \\
\text { bradykinesia, correlations of ACT sleep } \\
\text { variables with self-reported measures of } \\
\text { sleep could only be found in PD-patients } \\
\text { and not in healthy controls. } \\
\text { Assessment was performed over seven days } \\
\text { with sufficient data. } \\
\text { As the PKG can differentiate bradykinesia } \\
\text { and complete immobility by a defined } \\
\text { threshold, the PKG might even be able to } \\
\text { discriminate sleep pattern in between PD- } \\
\text { patients. }\end{array}$ \\
\hline $\begin{array}{l}\text { Nass et al. } \\
\text { [17] }\end{array}$ & $\begin{array}{l}\text { 24-hour ACT over three days } \\
\text { to compare how the daytime } \\
\text { and nighttime motor activity } \\
\text { levels in } 69 \text { individuals } \\
\text { without motor disorders differ }\end{array}$ & $\begin{array}{l}\text { - ACT showed increased (1.5 to 2-fold) nighttime motor } \\
\text { activity in PD-patients in comparison to healthy controls } \\
\text { - older controls showed a lower daytime but similar } \\
\text { nighttime motor activity when compared to younger controls } \\
\text { - a ratio of nighttime to daytime motor activity could clearly }\end{array}$ & $\begin{array}{l}\text { As there was higher nighttime motor } \\
\text { activity in PD-patients compared to healthy } \\
\text { controls and sleep disturbances are more } \\
\text { common in PD-patients when compared to } \\
\text { controls, nighttime motor activity might }\end{array}$ \\
\hline
\end{tabular}

This article is protected by copyright. All rights reserved 


\begin{tabular}{|c|c|c|c|}
\hline & from 17 PD-patients & distinguish controls and PD-patients. & $\begin{array}{l}\text { correspond to wakefulness or abnormal } \\
\text { sleep. Therefore nighttime mobility as } \\
\text { measured by ACT might correspond to } \\
\text { disturbed sleep. }\end{array}$ \\
\hline $\begin{array}{l}\text { Hauser etal. } \\
2000[18] \text { and } \\
2004[19]\end{array}$ & $\begin{array}{l}\text { Validation of the Parkinson`s } \\
\text { disease home diary (Hauser- } \\
\text { diary) in } 302 \text { PD-patients }\end{array}$ & $\begin{array}{l}\text { - } 83 \% \text { of patients completed six diaries without missing or } \\
\text { duplicate data } \\
\text { - } 96 \% \text { completed six diaries with less than five hours of } \\
\text { errors on any diary } \\
-76 \% \text { of missing or duplicate data occurred after three days } \\
\text { of assessment }\end{array}$ & $\begin{array}{l}\text { Six consecutive } 24 \text {-hour periods resulting in } \\
\text { six days and five nights of Hauser-diary } \\
\text { completion are validated. }\end{array}$ \\
\hline $\begin{array}{l}\text { Jean-Louis et al. } \\
2001[20]\end{array}$ & $\begin{array}{l}\text { Different ACT modalities and } \\
\text { overnight PSG in } 5 \text { subjects, } \\
\text { classified as normal or with } \\
\text { sleep or emotional disorders }\end{array}$ & $\begin{array}{l}\text { - Comparisons showed 91-93\% overall agreement for total } \\
\text { sleep time of ACT and PSG }\end{array}$ & $\begin{array}{l}\text { ACT can assess nighttime sleep in subjects } \\
\text { with and without sleep disorders. Therefore } \\
\text { PKG should be able to assess nighttime } \\
\text { sleep in PD-patients. }\end{array}$ \\
\hline $\begin{array}{l}\text { Kushida et } \\
2001[21]\end{array}$ & $\begin{array}{l}\text { ACT, overnight PSG and } \\
\text { subjective sleep reports in } 100 \\
\text { subjects with different sleep } \\
\text { disorders (insomnia, OSAS, } \\
\text { narcolepsy, restless legs } \\
\text { syndrome) }\end{array}$ & $\begin{array}{l}\text { - ACT overestimated total sleep time and sleep efficiency in } \\
\text { comparison to subjective patient reports } \\
\text { - the number of nocturnal awakenings did not differ } \\
\text { significantly between ACT and PSG while self-reports did } \\
\rightarrow \text { ACT was more accurate than the patient's subjective } \\
\text { reports }\end{array}$ & $\begin{array}{l}\text { ACT is more accurate than the patient's } \\
\text { subjective reports. }\end{array}$ \\
\hline Jean-Louis et al. & Wrist ACT, overnight PSG & - significant correlation for total sleep time $\left(\mathrm{r}_{\mathrm{s}}=0.68\right)$ and & Results are used for the definition of \\
\hline
\end{tabular}

This article is protected by copyright. All rights reserved 


\begin{tabular}{|c|c|c|c|}
\hline 1999 [14] & $\begin{array}{l}\text { and sleep/wake diaries in } 26 \\
\text { subjects with insomnia }\end{array}$ & $\begin{array}{l}\text { sleep efficiency }\left(\mathrm{r}_{\mathrm{s}}=0.52\right) \text { of PSG and ACT were found if a } \\
\text { threshold of } 10 \text { actigraphic counts and a wake interval post } \\
\text { arousal of } 3 \text { min is used as criteria for discriminating sleep } \\
\text { from wakefulness } \\
\text { - beginning of sleep determined by the appearance of the } \\
\text { first } 15 \text { min of consecutive counts below a defined ACT } \\
\text { sleep threshold }\end{array}$ & $\begin{array}{l}\text { nighttime sleep quantity and quality } \\
\text { parameters of the PKG. }\end{array}$ \\
\hline $\begin{array}{l}\text { Monk et al } \\
1999[22]\end{array}$ & $\begin{array}{l}\text { ACT, sleep diaries and PSG in } \\
4 \text { healthy subjects }\end{array}$ & $\begin{array}{l}\text { - predicted values of ACT were clearly superior to those of } \\
\text { sleep diaries for sleep onset and offset, sleep duration, } \\
\text { and sleep efficiency compared to PSG. }\end{array}$ & $\begin{array}{l}\text { Results are used for the definition of } \\
\text { nighttime sleep quantity and quality } \\
\text { parameters of the PKG. }\end{array}$ \\
\hline $\begin{array}{l}\text { Ancoli-Israel et } \\
\text { al. 1997[23] }\end{array}$ & $\begin{array}{l}\text { ACT and overnight PSG in } 10 \\
\text { subjects with severe dementia }\end{array}$ & $\begin{array}{l}\text { - high correlations between ACT and PSG for total sleep } \\
\text { time }(0.81-0.91) \text { and for percent sleep }(0.61-0.78) \text { could } \\
\text { be revealed. }\end{array}$ & $\begin{array}{l}\text { ACT can assess nighttime sleep in subjects } \\
\text { with a neurodegenerative disorder. }\end{array}$ \\
\hline $\begin{array}{l}\text { Sadeh et al. } \\
1996[24]\end{array}$ & $\begin{array}{l}\text { ACT and parental sleep logs in } \\
66 \text { infants }\end{array}$ & $\begin{array}{l}\text { - minimum of seven nights of ACT were needed to get five } \\
\text { nights of useful data for sleep onset and the number of } \\
\text { minutes of wake state }\end{array}$ & $\begin{array}{l}\text { To obtain sufficient nighttime data six } \\
\text { consecutive } 24 \text {-hour periods resulting in } \\
\text { five nights were needed. }\end{array}$ \\
\hline $\begin{array}{l}\text { Gorny et al. } \\
1996[25] \\
\end{array}$ & Wrist ACT & $\begin{array}{l}\text { - more precise sleep/wake determinations were received if a } \\
\text { rule of } 2 \text { min of activity before and after an epoch of sleep } \\
\text { was applied in scoring ACT data }\end{array}$ & $\begin{array}{l}\text { Results are used for the definition of } \\
\text { nighttime sleep quantity and quality } \\
\text { parameters of the PKG. }\end{array}$ \\
\hline $\begin{array}{l}\text { Jean-Louis et al. } \\
1996[26]\end{array}$ & $\begin{array}{l}\text { Wrist ACT and overnight PSG } \\
\text { in } 20 \text { healthy subjects }\end{array}$ & $\begin{array}{l}\text { - ACT was highly correlated with PSG for differentiating } \\
\text { sleep/wake states }\left(r_{s}=0.97\right)\end{array}$ & $\begin{array}{l}\text { Results are used for the definition of } \\
\text { nighttime sleep quantity and quality }\end{array}$ \\
\hline
\end{tabular}

This article is protected by copyright. All rights reserved 


\begin{tabular}{|c|c|c|c|}
\hline & & $\begin{array}{l}\text { - individuals take about } 3 \text { min to return to sleep after } \\
\text { nocturnal awakenings as determined by PSG }\end{array}$ & parameters of the PKG. \\
\hline $\begin{array}{l}\text { Sadeh et al. } \\
1994[27]\end{array}$ & $\begin{array}{l}\text { ACT and overnight PSG in } 44 \\
\text { healthy subjects }\end{array}$ & $\begin{array}{l}\text { - comparisons showed 91.4-96.5\% minute-by-minute } \\
\text { agreement rates for sleep/wake scoring of ACT and PSG } \\
\text { - sleep/wake scoring from ACT is little affected by device } \\
\text { placement although activity levels differed between } \\
\text { dominant and non-dominant wrist during sleep and } \\
\text { wakefulness but resulting ability to discriminate sleep was } \\
\text { relatively unaffected by this. }\end{array}$ & $\begin{array}{l}\text { There are no differences in ACT sleep/wake } \\
\text { scoring concerning device placement on the } \\
\text { dominant versus non-dominant wrist. } \\
\text { Therefore, the PKG will be placed on the } \\
\text { more affected wrist concerning PD motor } \\
\text { symptoms for better assessment of the } \\
\text { severity of motor state of PD during } \\
\text { daytime. }\end{array}$ \\
\hline $\begin{array}{l}\text { Cole et al. } 199 \\
{[16]}\end{array}$ & $\begin{array}{l}\text { Wrist ACT and overnight PSG } \\
\text { in } 21 \text { subjects, classified as } \\
\text { normal or with sleep or } \\
\text { psychiatric disorders }\end{array}$ & $\begin{array}{l}\text { - } 88 \% \text { of the time asleep being distinguished from } \\
\text { wakefulness by ACT compared to PSG } \\
\text { - sleep onset defined as the beginning of the first interval } \\
\text { containing at least } 15 \text { min (at least } 20 \text { min) scored as sleep } \\
\text { stage I or greater with no more than } 1 \text { min of wakefulness in } \\
\text { PSG showed a high correlation ( } \mathrm{r}_{\mathrm{s}}=0.87 \text { and } \mathrm{r}_{\mathrm{s}}=0.94 \text {, } \\
\text { respectively) with ACT } \rightarrow \text { ACT provides a reliable estimate } \\
\text { of sleep onset time } \\
\text { - ACT sleep percentage and sleep latency correlated on a } \\
\text { high level ( } \mathrm{r}_{\mathrm{s}}=0.82 \text { and } \mathrm{r}_{\mathrm{s}}=0.90 \text {, respectively) with } \\
\text { corresponding parameters from PSG }\end{array}$ & $\begin{array}{l}\text { Results are used for the definition of } \\
\text { nighttime sleep quantity and quality } \\
\text { parameters of the PKG. }\end{array}$ \\
\hline
\end{tabular}

This article is protected by copyright. All rights reserved 


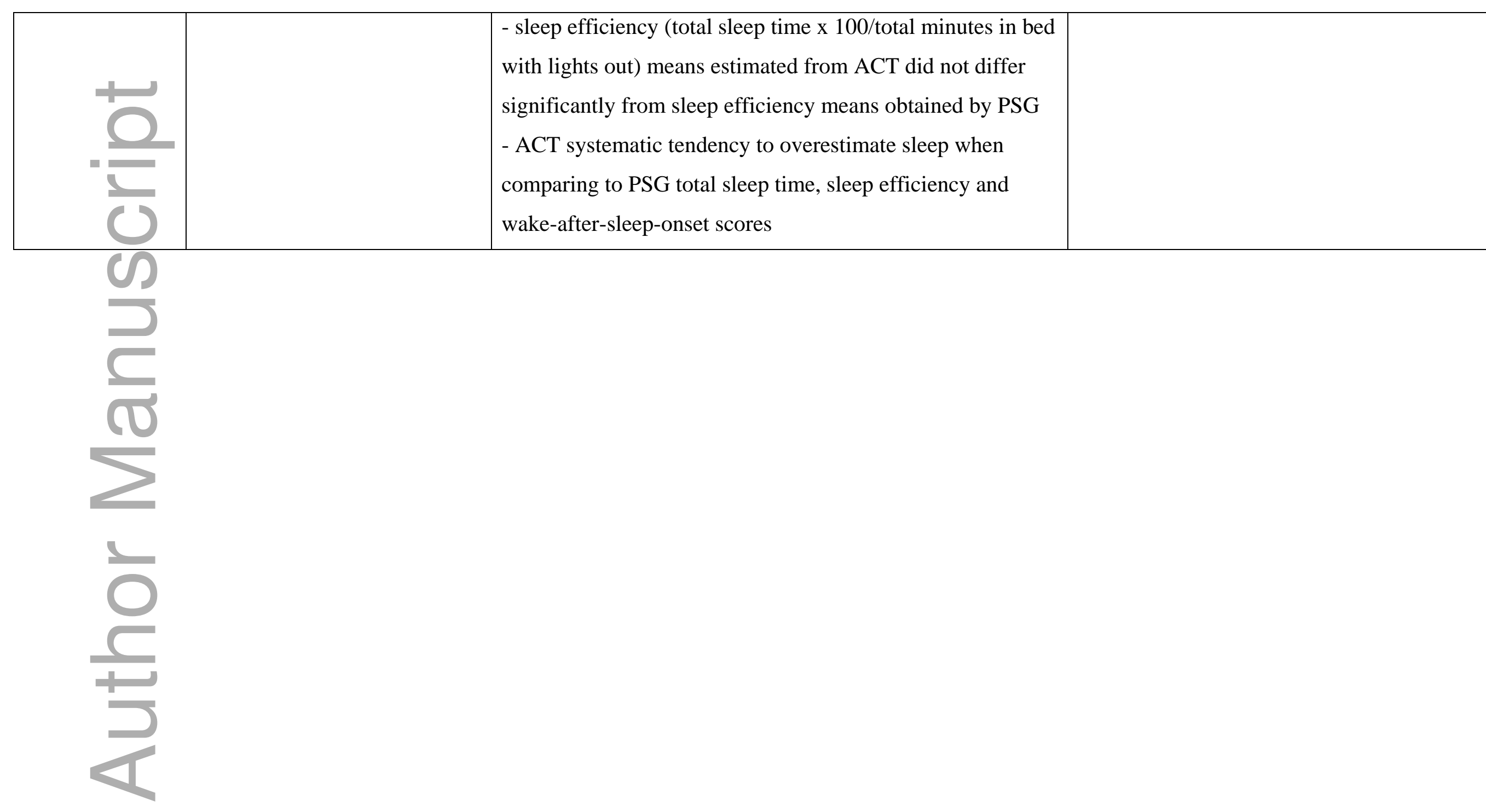

This article is protected by copyright. All rights reserved 
Table 2: Baseline characteristics and outcome measures

\begin{tabular}{|c|c|c|c|}
\hline $\begin{array}{c}\text { Baseline characteristics and } \\
\text { outcome measures }\end{array}$ & $\begin{array}{l}\text { Study group: } \\
\qquad \begin{array}{l}\text { PD-EDS } \\
(\mathbf{N}=\mathbf{3 0})\end{array}\end{array}$ & $\begin{array}{c}\text { Control group: } \\
\text { PD-NS } \\
(\mathbf{N}=\mathbf{3 3})\end{array}$ & p-values \\
\hline $\begin{array}{l}\text { Age (mean } \pm \text { standard deviation } \\
(\mathrm{SD}) \text { in years) } \\
\text { Range }\end{array}$ & $\begin{array}{l}61.87 \pm 7.39 \\
45.75-80.64\end{array}$ & $\begin{array}{l}63.17 \pm 12.24 \\
30.64-80.30\end{array}$ & 0.62 \\
\hline Male sex - no. $(\%)$ & $21(70.0)$ & $22(66.7)$ & 0.78 \\
\hline Ethnicity white - no. (\%) & $27(90.0)$ & $27(81.8)$ & 0.56 \\
\hline $\begin{array}{l}\text { Duration of disease (mean } \pm \mathrm{SD} \\
\text { in years) } \\
\text { Range }\end{array}$ & $\begin{array}{l}9.94 \pm 7.15 \\
0.32-33.42\end{array}$ & $\begin{array}{l}6.87 \pm 5.43 \\
0.33-18.34\end{array}$ & 0.07 \\
\hline $\begin{array}{l}\text { Levodopa equivalent dose } \\
\text { (mean } \pm \text { SD in mg per day) } \\
\text { Range }\end{array}$ & $\begin{array}{l}1136.06 \pm 686.48 \\
0.0-2602.0\end{array}$ & $\begin{array}{l}884.86 \pm 477.99 \\
0.0-2150.0\end{array}$ & 0.27 \\
\hline $\begin{array}{l}\text { H\&Y } \\
\quad \text { Median } \pm \text { interquartile range } \\
\text { Range }\end{array}$ & $\begin{array}{l}3.0 \pm 2-3 \\
1-4\end{array}$ & $\begin{array}{l}2.0 \pm 2-3 \\
1-5\end{array}$ & 0.73 \\
\hline $\begin{array}{l}\text { SCOPA Motor sum A } \\
\text { Mean } \pm \text { SD } \\
\text { Range }\end{array}$ & $\begin{array}{l}9.40 \pm 5.95 \\
0-26\end{array}$ & $\begin{array}{l}8.97 \pm 4.72 \\
2-19\end{array}$ & 0.75 \\
\hline $\begin{array}{c}\text { SCOPA Motor sum B } \\
\text { Mean } \pm \text { SD } \\
\text { Range }\end{array}$ & $\begin{array}{l}7.57 \pm 3.13 \\
2-14\end{array}$ & $\begin{array}{l}6.76 \pm 3.56 \\
1-15\end{array}$ & 0.34 \\
\hline $\begin{array}{c}\text { SCOPA Motor sum C } \\
\text { Mean } \pm \text { SD } \\
\text { Range }\end{array}$ & $\begin{array}{l}4.57 \pm 2.84 \\
0-9\end{array}$ & $\begin{array}{l}3.91 \pm 3.20 \\
0-11\end{array}$ & 0.24 \\
\hline $\begin{array}{l}\text { UPDRS IV sum A and B } \\
\text { Mean } \pm \text { SD } \\
\text { Range }\end{array}$ & $\begin{array}{l}6.07 \pm 3.50 \\
0-14\end{array}$ & $\begin{array}{l}4.79 \pm 3.24 \\
0-14\end{array}$ & 0.14 \\
\hline $\begin{array}{l}\text { AIMS sum score 1-7 } \\
\text { Mean } \pm \text { SD } \\
\text { Range }\end{array}$ & $\begin{array}{l}2.97 \pm 5.25 \\
0-16\end{array}$ & $\begin{array}{l}3.88 \pm 7.07 \\
0-23\end{array}$ & 0.98 \\
\hline
\end{tabular}




\begin{tabular}{|c|l|l|c|}
\hline $\begin{array}{c}\text { HADS } \\
\text { Mean } \pm \text { SD } \\
\text { Range }\end{array}$ & $\begin{array}{l}14.43 \pm 5.53 \\
3-24\end{array}$ & $\begin{array}{l}12.39 \pm 7.78 \\
2-31\end{array}$ & \\
\hline $\begin{array}{c}\text { NMS Quest 13 } \\
\text { Percentage of “yes" answer }\end{array}$ & 26.7 & 27.3 & 0.96 \\
\hline $\begin{array}{c}\text { NMS Quest 16 } \\
\text { Percentage of "yes" answer }\end{array}$ & 50.0 & 45.5 & 0.72 \\
\hline $\begin{array}{c}\text { NMS Quest 17 } \\
\text { Percentage of “yes" answer }\end{array}$ & 53.3 & 36.4 & 0.18 \\
\hline $\begin{array}{l}\text { PDQ 8 sum total score } \\
\text { Mean } \pm \text { SD } \\
\text { Range }\end{array}$ & $10.73 \pm 5.09$ & $8.58 \pm 5.77$ & 0.07 \\
\hline
\end{tabular}

Table 3: Mean nighttime sleep quantity measures of one night

\begin{tabular}{|l|c|c|c|c|}
\hline Nighttime sleep quantity measures & \multicolumn{2}{c|}{$\begin{array}{c}\text { Study group: } \\
\text { PD-EDS }\end{array}$} & \multicolumn{2}{c|}{$\begin{array}{c}\text { Control group: } \\
\text { PD-NS }\end{array}$} \\
\hline PKG & mean & range & mean & range \\
\hline Duration of Rest (hrs:mins) & $7: 34$ & $1: 21-11: 01$ & $8: 17$ & $4: 07-11: 33$ \\
\hline Duration of Sleep (hrs:mins) & $4: 04$ & $0: 17-7: 35$ & $4: 40$ & $0: 43-7: 26$ \\
\hline Duration of Wakefulness (hrs:mins) & $3: 38$ & $0: 12-8: 15$ & $3: 26$ & $0: 32-8: 04$ \\
\hline Diary & mean & range & mean & range \\
\hline Duration of Sleep (hrs:mins) & $6: 18$ & $2: 48-9: 18$ & $6: 50$ & $3: 48-9: 48$ \\
\hline Duration of Wakefulness (hrs:mins) & $5: 20$ & $2: 24-7: 12$ & $5: 06$ & $2: 12-8: 12$ \\
\hline
\end{tabular}


Table 4: Correlations between PKG measures, Hauser-diary and subjective questionnaires of nighttime sleep in the PD-EDS and PD-NS group. Correlation coefficient as $\mathrm{r}_{\mathrm{s}}$-values, significance levels $\mathrm{p}$-values as $*_{\mathrm{p}}<0.05$; ** $\mathrm{p}<0.01$; *** $<0.001$, values of PD-NS group in brackets.

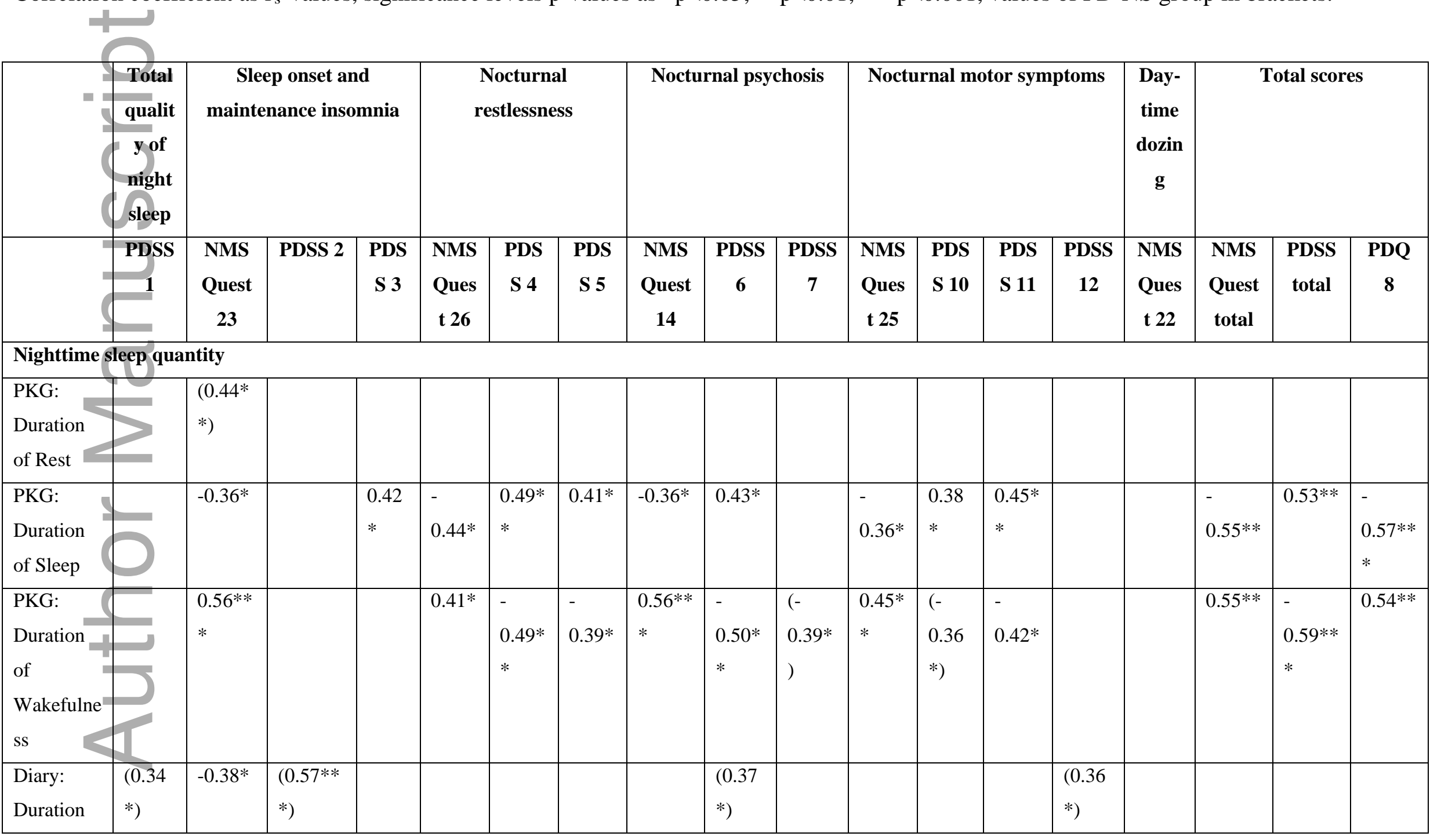

This article is protected by copyright. All rights reserved 


\begin{tabular}{|c|c|c|c|c|c|c|c|c|c|c|c|c|c|c|c|c|}
\hline of Sleep & & & & & & & & & & & & & & & & \\
\hline $\begin{array}{l}\text { Diary: } \\
\text { Duration } \\
\text { of } \\
\text { Wakefulne } \\
\text { ss }\end{array}$ & & $\begin{array}{l}(- \\
0.48 * *)\end{array}$ & & $0.39 *$ & & & & & & & & & & & & \\
\hline \multicolumn{17}{|c|}{ Nighttime sleep quality } \\
\hline $\begin{array}{l}\text { PKG: PTI } \\
\text { asleep }\end{array}$ & $\begin{array}{l}- \\
0.57 * * \\
*\end{array}$ & & & $\begin{array}{l}- \\
0.49 * \\
*\end{array}$ & $\begin{array}{l}0.46^{*} \\
*\end{array}$ & $\begin{array}{l}0.46^{*} \\
*\end{array}$ & $\begin{array}{l}- \\
0.49 * *\end{array}$ & $\begin{array}{l}0.52 * \\
*\end{array}$ & $\begin{array}{l}(0.38 \\
*)\end{array}$ & $\begin{array}{l}0.38 \\
*\end{array}$ & $\begin{array}{l}0.45^{*} \\
*\end{array}$ & $0.41 *$ & & $\begin{array}{l}- \\
0.66^{* *} \\
*\end{array}$ & $\begin{array}{l}0.68 * * \\
*\end{array}$ & $\begin{array}{l}- \\
0.59 * * \\
*\end{array}$ \\
\hline $\begin{array}{l}\text { PKG: PTI } \\
\text { asleep } \\
>20 \mathrm{~min}\end{array}$ & $-0.37 *$ & & $\begin{array}{l}0.43 \\
*\end{array}$ & $\begin{array}{l}- \\
0.40 *\end{array}$ & & $0.37 *$ & $-0.36 *$ & $\begin{array}{l}0.52 * \\
*\end{array}$ & & $\begin{array}{l}0.41 \\
*\end{array}$ & & $0.43^{*}$ & $\begin{array}{l}- \\
0.38^{*}\end{array}$ & $\begin{array}{l}- \\
0.57 * * \\
*\end{array}$ & $\begin{array}{l}0.57 * * \\
*\end{array}$ & $\begin{array}{l}- \\
0.46^{* *}\end{array}$ \\
\hline $\begin{array}{l}\text { PKG: PTI } \\
\text { awake } \\
>20 \mathrm{~min}\end{array}$ & $0.54 * *$ & & & $\begin{array}{l}0.46^{*} \\
*\end{array}$ & $\begin{array}{l}- \\
0.47 * \\
*\end{array}$ & $\begin{array}{l}- \\
0.46^{*} \\
*\end{array}$ & $0.50 * *$ & $\begin{array}{l}- \\
0.54 * \\
*\end{array}$ & $\begin{array}{l}- \\
0.41 * \\
)\end{array}$ & $\begin{array}{l}- \\
0.38 \\
*\end{array}$ & $\begin{array}{l}- \\
0.45^{*} \\
*\end{array}$ & $\begin{array}{l}- \\
0.40 *\end{array}$ & & $\begin{array}{l}0.65^{* *} \\
*\end{array}$ & $\begin{array}{l}- \\
0.68 * * \\
*\end{array}$ & $\begin{array}{l}0.60 * * \\
*\end{array}$ \\
\hline
\end{tabular}

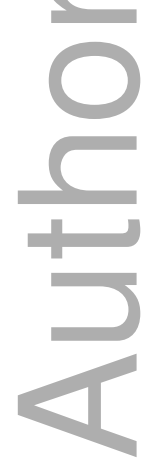

This article is protected by copyright. All rights reserved 


\section{Figure Legends}

Figure 1: Example of a PKG (1a,b,c) and Hauser-diary (1d) extract.

Figure 1a: Summary plot of mobility data recorded for one patient wearing the PKG for six days and the corresponding 5 nights. The time is represented across the top of the plot from 2 minutes after midnight (0:02) till midnight (0:00). Values for dyskinesia (thick green line representing the median, thin green lines the $25^{\text {th }}$ and $75^{\text {th }}$ percentile) are shown in the top half with dyskinesia increasing from the midpoint upwards. Values for bradykinesia (thick blue line representing the median, thin blue lines the $25^{\text {th }}$ and $75^{\text {th }}$ percentile) are shown in the bottom half with bradykinesia increasing from the midpoint downwards. The horizontal lines represent the $50^{\text {th }}, 75^{\text {th }}$ and $90^{\text {th }}$ percentile of control subjects concerning bradykinesia and dyskinesia scores

Figure $1 \mathrm{~b}$ and 1c: Immobility summary of the PKG with the time from 2 minutes after midnight (0:02) till midnight (0:00) on the $\mathrm{x}$-axis and the single days on the $\mathrm{y}$-axis. The black segments are immobility epochs, the white segments correspond to mobility. The blue vertical lines mark the start and end point of the "duration of nighttime rest" for three nights respectively (1b: Eri 20th-Sat 21st, Sun 22nd-Mon 23rd, Tue 24th-Wed 25th; 1c: Thu 13rdFri 14th, Sat 15th-Sun 16th, Mon 17th-Tue 18th). The red vertical lines mark immobility as black segments for the "duration of sleep" (example marked by yellow arrow) and mobility as white segments for the "duration of wakefulness" (example marked by yellow arrow), respectively. Figure $1 \mathrm{~b}$ provides an example for good nighttime sleep and 1c for disturbed nighttime sleep.

Figure 1d: Two days of Hauser-diary with the time from 6:00AM till 5:30AM on the y-axis and asleep as well as different mobility scores (OFF, ON without dyskinesia, ON with nontroublesome dyskinesia, $\mathrm{ON}$ with troublesome dyskinesia) on the $\mathrm{x}$-axis. The patients are asked to cross on a half-hour base (one cross per line) for one predominant state (asleep or one mobility score). Nighttime is marked with blue horizontal lines and a blue arrow from 8:00PM till 8:00AM. The sleep period is marked with red horizontal lines.

Figure 2: Scatterplot of PKG nighttime sleep quantity measures (x-axis) and total scores of NMSQuest, PDSS and PDQ8 (y-axis). Duration of sleep (blue dots) and duration of wakefulness (green crosses) with a) NMSQuest, b) PDSS, c) PDQ8 in the PD-EDS group, d) NMSQuest, e) PDSS, f) PDQ8 in the PD-NS group. Corresponding regression lines. 
19: Neery aza oese Phe
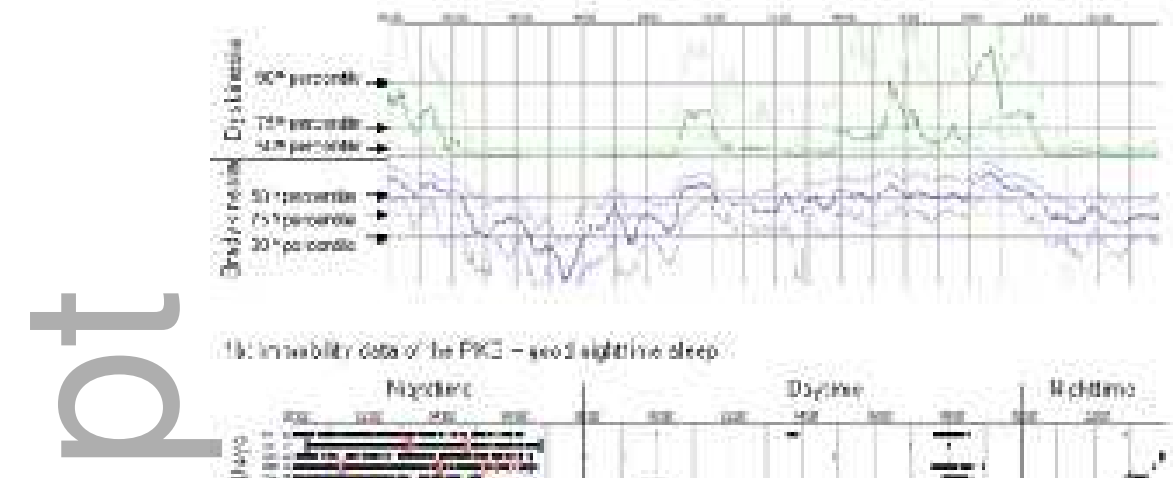

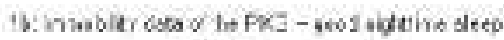

$$
\square
$$
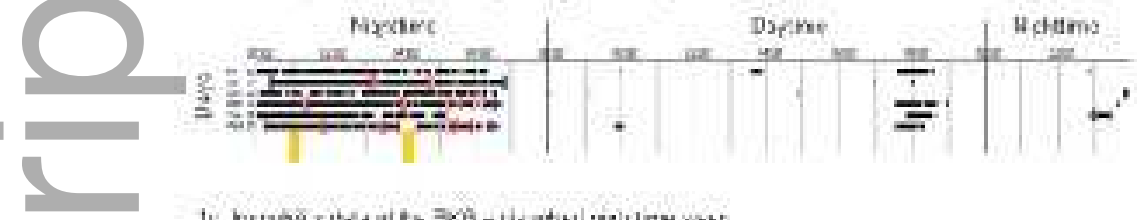

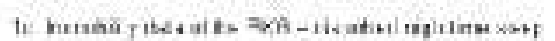
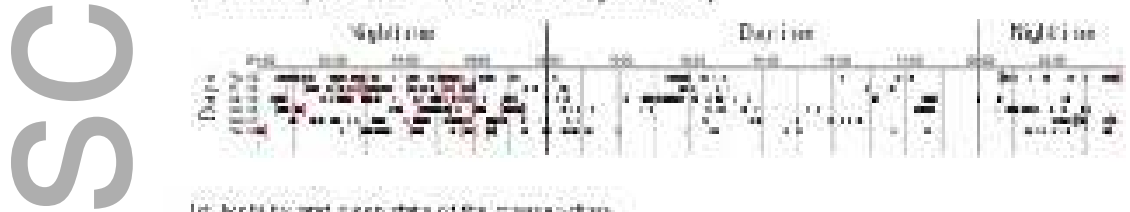

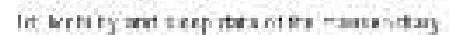
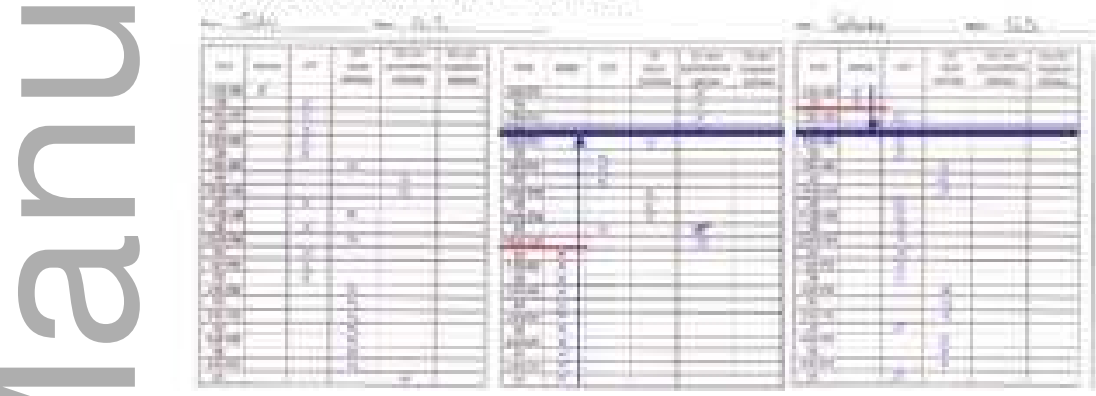

ene_13015_f1.tif

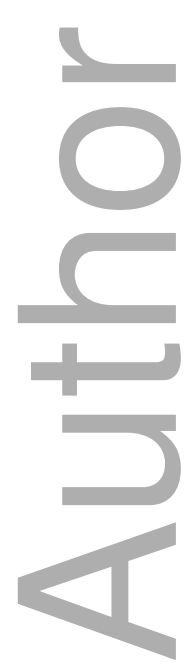


PD-EDS

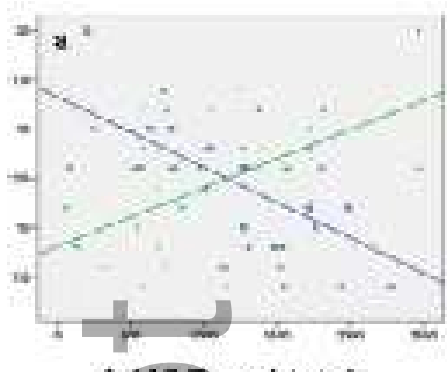

MMSCuest total
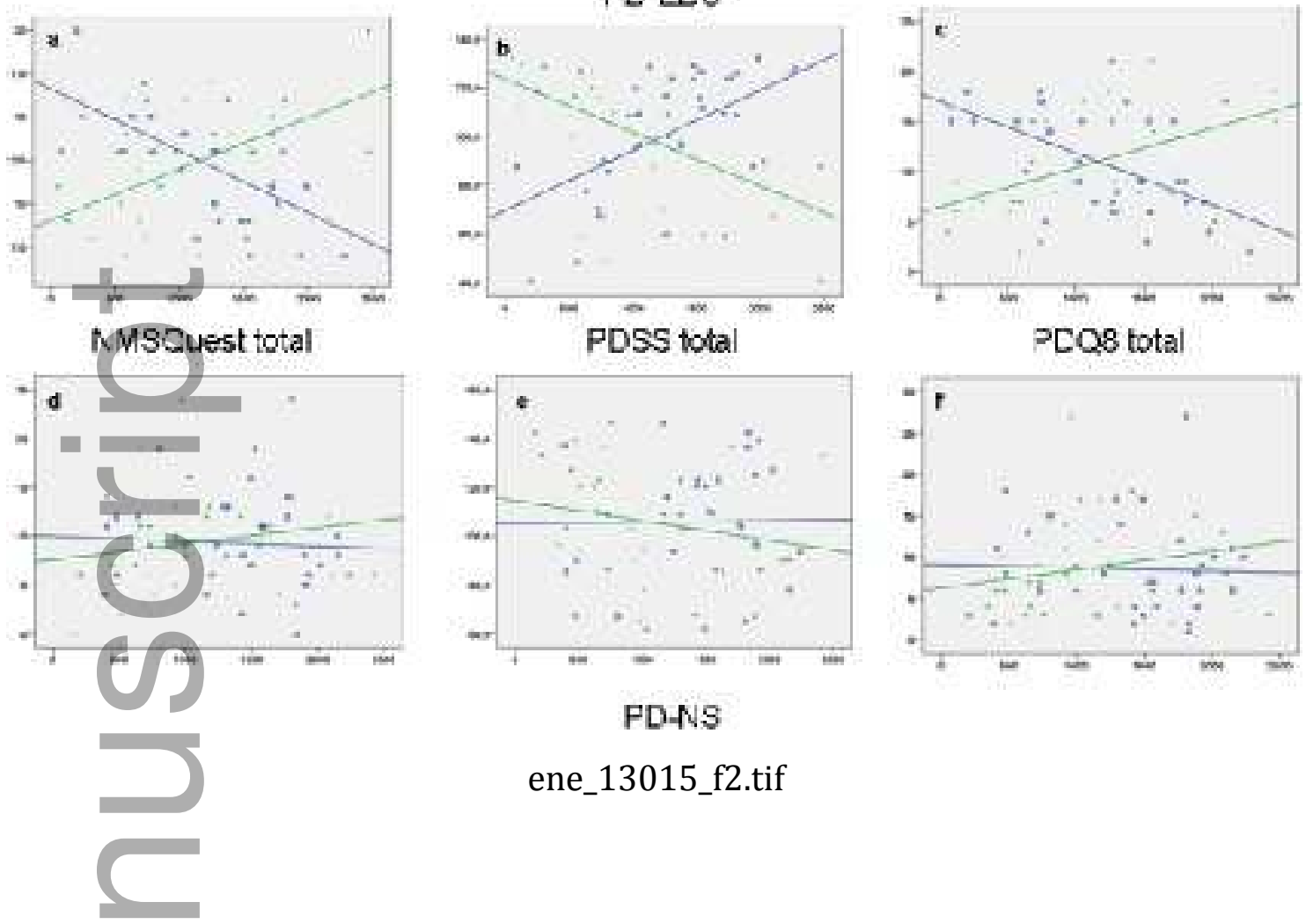

PD-NS

ene_13015_f2.tif
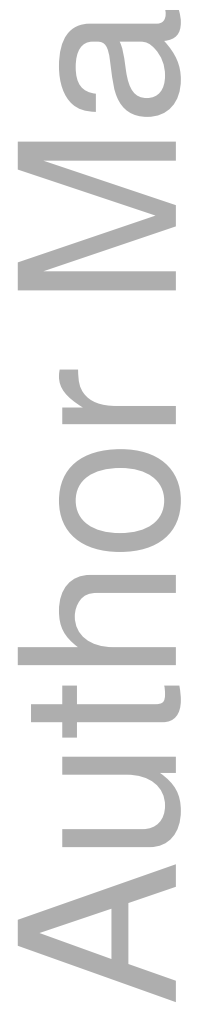


\section{University Library}

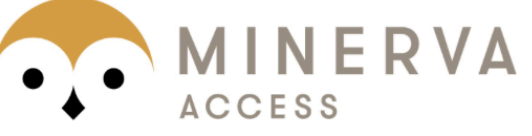

A gateway to Melbourne's research publications

Minerva Access is the Institutional Repository of The University of Melbourne

Author/s:

Klingelhoefer, L;Rizos, A;Sauerbier, A;McGregor, S;Martinez-Martin, P;Reichmann, H;Horne, $\mathrm{M}$;Chaudhuri, KR

Title:

Night-time sleep in Parkinson's disease - the potential use of Parkinson's KinetiGraph: a prospective comparative study

Date:

2016-08-01

Citation:

Klingelhoefer, L., Rizos, A., Sauerbier, A., McGregor, S., Martinez-Martin, P., Reichmann, H., Horne, M. \& Chaudhuri, K. R. (2016). Night-time sleep in Parkinson's disease - the potential use of Parkinson's KinetiGraph: a prospective comparative study. EUROPEAN JOURNAL OF NEUROLOGY, 23 (8), pp.1275-1288. https://doi.org/10.1111/ene.13015.

Persistent Link:

http://hdl.handle.net/11343/291299 